\title{
Kommunikationsformen des Internetzeitalters im Lichte der Komunikationsfreiheiten des Grundgesetzes
}

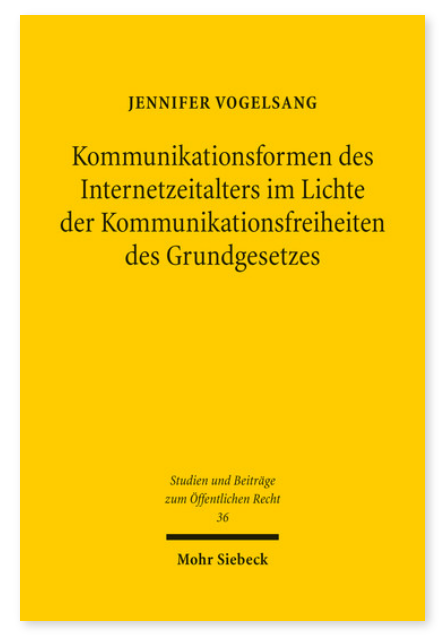

2017. XXII, 282 Seiten. StudÖR 36

ISBN 978-3-16-155379-0

DOI 10.1628/978-3-16-155379-0

eBook PDF $94,00 €$

ISBN 978-3-16-155378-3

fadengeheftete Broschur 94,00€
Die modernen Kommunikationsmedien durchdringen seit dem Siegeszug der digitalen Revolution den Alltag eines jeden und beeinflussen das gesellschaftliche Miteinander tiefgreifend. Internetbasierte Technologien bieten neue Möglichkeiten des Austauschs und des Zusammenwirkens. Diese historisch gesehen immer noch jungen Entwicklungen werfen eine Vielzahl verfassungs- und verwaltungsrechtlicher Fragen auf, die Jennifer Vogelsang ausgehend von einer kommunikations- bzw. sozialwissenschaftlichen Analyse beleuchtet. Sie zeigt die Möglichkeiten der Ausübung kommunikativer Freiheiten im virtuellen Raum auf und entwickelt Maßstäbe für einen verhältnismäßigen Interessenausgleich. Auf der Grundlage einer zeitgemäßen Auslegung belegt sie, dass die Kommunikationsfreiheiten auch im virtuellen Raum verwirklicht werden können.

Jennifer Vogelsang Geboren 1987; Studium der Rechtswissenschaften an der Ruhr-Universität Bochum; Wissenschaftliche Mitarbeiterin am Lehrstuhl für Öffentliches Recht und Europarecht an der Ruhr-Universität Bochum; seit 2015 Referendarin am Landgericht Bochum; 2017 Promotion.
Jetzt bestellen:

https://mohrsiebeck.com/buch/kommunikationsformen-des-internetzeitalters-im-lichte-der-komunikationsfreiheiten-desgrundgesetzes-9783161553790?no_cache=1

order@mohrsiebeck.com

Telefon: $+49(0) 7071-923-17$

Telefax: $+49(0) 7071-51104$ 